\title{
EVALUATING ENERGY CONSUMPTION EFFICIENCY IN TOBACCO PRODUCTION: APPLYING DATA ENVELOPMENT ANALYSIS
}

\author{
Zulqarnain Mushtaq ${ }^{1}$, Wei Wei'2, Maimoona Sharif', \\ Abbas Ali Chandio ${ }^{4}$
}

Xi'an Jiaotong University, School of Economics \& Finance, China, ORCID: 0000-0003-4564-5518,
zulqarnain@stu.xjtu.edu.cn;
Xi'an Jiaotong University, School of Economics \& Finance, China, ORCID: 0000-0002-7469-1997,
wei_wei@mail.xjtu.edu.cn (corresponding author);
Xi'an Jiaotong University, School of Chemical Engineering and Technology, China, ORCID: 0000-0001-6526-4726,
Mona.chem@stu.xjtu.edu.cn;
Sichuan Agriculture University, College of Economics, China, ORCID: 0000-0002-1063-3384, alichandio@sicau.edu.cn.

\begin{abstract}
Tobacco is considered as one of the most important industrial cash crop and source of livelihood to many families in Pakistan. Considering the contraction of land under tobacco cultivation, the present study is intended to evaluate the production efficiency of tobacco growers in southern Punjab, Pakistan. The Data Envelopment Analysis model was used to investigate energy usage efficiency of tobacco farmers based on seven energy inputs; human labour, farm machinery, irrigation, diesel, fertilizers, chemicals, seeds, and a single output. Moreover, the current study also used DEA - super efficiency to identify and rank efficient and inefficient tobacco producers; and to suggest optimum energy requirements and energy savings potentials. The primary data from 210 tobacco growers were collected in-person interviews by random sampling technique. The findings of the study revealed that average energy consumed in the form of inputs and yield obtained in tobacco production was 52,703.58 $\mathrm{MJ} / \mathrm{ha}^{-1}$ and 3,096.98 $\mathrm{MJ} / \mathrm{ha}^{-1}$, respectively. Average technical, pure technical, and scale efficiency score was calculated to be 0.902, 0.961, and 0.938, respectively. Likewise, the energy-saving ratio in tobacco production was estimated to be $13.83 \%$, which implies that by adopting the proposed recommendations about 7,121.66 MJ/ha-1 energy could be saved without compromising the output. Also, fertilizers, chemicals, irrigation, and diesel had the highest share in the consumption of energy inputs. The findings of the study provides pinpoint options to the agricultural polices makers to launch the technical training programs for the tobacco farmers to adopt better management practices to optimize the application of energy inputs to reduce the cost of tobacco production. The agricultural extension department should also visit the tobacco fields to assist the farmers about timely application of inputs and with extension services.
\end{abstract}

Keywords: Energy efficiency, energy inputs, Data Envelopment Analysis, energy consumption, energy saving potentials, energy conservation, slacked based super efficiency.

JEL Classifications: Q01, Q56, Q42.

APA Style Citation: Mushtaq, Z., Wei, W., Sharif, M., \& Chandio, A. A. (2021). Evaluating Energy Consumption Efficiency in Tobacco Production: Applying Data Envelopment Analysis. E\&M Economics and Management, 24(3), 23-39. https://doi.org/10.15240/tul/001/2021-03-002

\section{Introduction}

Tobacco is one of the most important cash crops and is considered as a domineering industrial crop. Tobacco is more proficient than any other crops to produce a massive amount of biofuel if cultivated for energy production instead of smoking (Andrianov et al., 2010). Pakistan is the world's $8^{\text {th }}$ largest tobacco producer 
(Shahbandeh, 2020). Over 75,000 farmers are cultivating tobacco in Pakistan. The crop was cultivated about on 51,000 hectars with a total production of 113,000 tones during 2017 (GOP, 2018). Tobacco crop got a significant place in the economy of the country by accommodating 350,000 workers directly and indirectly and is also adding up revenue of over Rs. 300 billion per annum. It is also providing a livelihood to about 1.2 million people in the country (Board, 2018). It is worth mentioning that tobacco has witnessed a decrease in production during 2016 with negative growth of 2.6 percent, over the same period last year (GOP, 2018).

Energy has become the fundamental factor for the socio-economic development of any region, country, or sector. Energy consumption analysis and scientific research on energy efficiency can help policymakers to design future energy policies and strategies (Wei et al., 2020c). Agriculture sector not only consumes energy but also produces energy (Alam et al., 2005). Nowadays the energy demand is escalating at an increasing rate in agriculture due to growing population pressure and high living standards with limited arable land; thus to meet these needs, farmers are applying inputs inefficiently and superfluously, especially when inputs have easy access and low prices. The improvements in energy consumption efficiency can not only be cost-effective but also can reduce energy-related environmental degradation issue, which ultimately contributes to sustainable development (Mousavi-Avval et al., 2011b).

Plenty of studies had estimated energy efficiency for different crops using parametric and non-parametric techniques; such as Kizilaslan (2009) conducted a study using the non-parametric approach to investigate energy consumption efficiency for cherries production in Turkey, Mohammadi and Omid (2010) on greenhouse cucumber in Iran, Singh et al. (1988) in six different agro-climatic zones of Indian Punjab. Ozkan et al. (2004) in greenhouse vegetables, Mandal et al. (2002) on soybean in India, Alimagham et al. (2017) on soybean in Iran, Pishgar-Komleh et al. (2012) on potato crop in Iran, Hatirli et al. (2005) in agriculture production in Turkey, Singh et al. (2004) on wheat production in India, Mohammadi et al. (2008) on potato in Iran, Hatirli et al. (2006) on tomato in Turkey, and Unakıtan and Aydın (2018) established an economic compression and energy use analysis of wheat and sunflower applying energy input-output ratio, energy inputs to output ratio and energy productivity (i.e. yield to energy input ratio).

Data Envelopment Analysis (DEA) is known as a non-parametric approach. DEA classifies efficient and inefficient decision-making units (DMUs) by benchmarking the best DMU. In addition to that, DEA is more superior to the parametric approach because it does not need any predefine assumptions to make a functional relationship among inputs and outputs (Mousavi-Avval et al., 2011b). One of the main advantages of DEA is that it can simultaneously evaluate several inputs and outputs (Zhang et al., 2009). Whereas; parametric models are the instrument for comparing the performance of decision-making units which uses a single input or a single output. However, the assessment of the performance of DMUs by parametric models using multiple inputs and multiple outputs requires the use of the complex process of simultaneous formulas which are fitted to the input-output data (Thanassoulis, 1993). Application of DEA in agriculture also has significant importance; such as Wei et al. (2020a) applied DEA model to find the social economic factors affecting cotton production in Pakistan, Mohammadi et al. (2011) who applied DEA model to analyze energy efficiency in kiwi production to calculated technical, pure technical and scale efficiency score, Kuhn et al. (2018) used DEA to quantify technical and environmental efficiency of livestock farms in China, Heidari et al. (2011) measured technical efficiency of poultry farms, Liu (2015) designed economic efficiency of agriculture using DEA, Mobtaker et al. (2012) used DEA to find energy optimization in alfalfa production, Wang et al. (2018) established a study to maximize agriculture water use efficiency in China, Mousavi-Avval et al. (2011a) used DEA to estimate input cost and apple production in Iran, Khoshnevisan et al. (2013) applied DEA to reduce greenhouse gas (GHG) emissions and energy efficiency in wheat production, Mardani and Salarpour (2015) estimated technical efficiency in potato production in Iran, Nasiri and Singh (2010) calculated energy efficiency for paddy crop in India, Abbas et al. (2018a) carried out a study in Pakistan to optimize energy usage efficiency of corn farms using DEA non-parametric approach.

On the bases of the existing literature only three studies were conducted to just estimate 
energy efficiency in tobacco production, such as: Loghmanpour-Zarini and Abedi-Firouzjaee (2013), Baran and Gokdogan (2015) and Moraditochaee (2012) calculated energy efficiency in tobacco production by applying simple energy input-output ratio methods but specifically no study has been carried out using DEA non-parametric approach in tobacco production. Moreover, there was no study on the optimization of energy consumption efficiency for tobacco production in Pakistan, either the DEA approach or the input-output ratio method. To shorten this research gap, the current study based on DEA super efficiency approach is unique in this respect in tobacco production. The objectives of the current study are to explore energy consumption patterns for tobacco production and to distinguish the super-efficient farmers by using DEA super efficiency approach, ranking the efficient and inefficient farmers and propose recommendations for the optimum energy requirements and energy savings for tobacco production in the Punjab province of Pakistan.

\section{Materials and Methods \\ 1.1 Selection of Study Area and Sampling Technique}

The area of the study is located at the center of Pakistan near the river Indus belt. Rajanpur is an important district of Punjab. This district was selected to undertake the current study as all farmers have homogenous playing fields which satisfy the underlying assumption of the DEA model. Therefore, the farmers' technical efficiency will not be exaggerated by external biophysical factors (e.g., soil type, weather, and topography).

In order to draw an accurate sample to represent the population, first of all, an accessible population in which every tobacco grower had an equal and independent chance of being included in the sample was determined. For this purpose, 21 villages from district Rajanpur were selected. As district directorates did not have an updated list of tobacco growers for every village, therefore, these villages were visited in advance to determine the tobacco growers and the area under tobacco cultivation. The lists of tobacco farmers from the 21 villages made the accessible population. Based on the area under tobacco cultivation by each farmer, the accessible population was divided into three strata. Then following the formula applied by
Boz (2015) stratified sample size determination formula was used by accepting a $5 \%$ error term from the mean and $95 \%$ confidence interval:

$$
n=\frac{N \sum S_{h}^{2} N_{h}}{N^{2} D^{2}+S_{h}^{2} N_{h}}, D^{2}=\frac{e^{2}}{t^{2}}
$$

Whereas $n$ is the prerequisite sample size, $N$ is the number of farmers in the accessible population, $N_{h}$ represents the number of tobacco growers in each stratum, $S_{h}$ shows the standard deviation within each stratum, $D^{2}$ is the desired variance, $e$ is accepted the error from the mean of the accessible population, $t$ is the t-table value of the accepted confidence interval. Subsequently, the calculated required sample of 210 tobacco farmers from 21 villages was randomly selected for interviews.

\subsection{Conversion of Inputs and Outputs to Energy Equivalents}

The first-hand data collected from tobacco producers included all kinds of inputs mainly human labour, irrigation water, diesel fuel, farmyard manure, agriculture machinery, seed, fertilizers (including nitrogen, potash, phosphorus) and chemicals in the form of herbicides and pesticides whereas tobacco yield was taken as the output.

Moreover, to estimate the energy efficiency by applying DEA model, the present study converted all the agricultural inputs and outputs data into their respective energy equivalents mega joules (MJ). As the present study is carried out in Pakistan and unfortunately, no study was found that especially calculated coefficients of energy equivalents for Pakistan condition, But, the literature is abundant that suggest the energy equivalents for different agricultural inputs and outputs such as; Mousavi-Avval et al. (2011a), Ebrahimi and Salehi (2015) and Pahlavan et al. (2011) calculated energy efficiency for canola, mushrooms and tomato crops by using these energy equivalents. Moreover, many researchers from Pakistan, such as Abbas et al. (2018b), Kousar et al. (2006), and Afzal and Ahmad (2009) also used these energy equivalents to convert the quantities of physical agricultural inputs and outputs to their respective energy equivalents (MJ). Therefore the present study also used the existing coefficients of energy equivalents to convert the agricultural inputs and outputs to 
Tab. 1: Tobacco inputs \& outputs energy equivalents

\begin{tabular}{l|l|c|l}
\multicolumn{1}{c|}{ Inputs \& outputs } & \multicolumn{1}{c|}{ Units } & $\begin{array}{c}\text { Energy equivalent } \\
\text { MJ/unit }\end{array}$ & \multicolumn{1}{c}{ References } \\
\hline Inputs & & & \\
\hline 1. Human labor & Hours $(\mathrm{h})$ & 1.96 & Ashkan et al., 2016 \\
\hline 2. Machinery & & & \\
\hline \multicolumn{1}{c|}{ a) Tractor } & (h) & 93.61 & Canakci et al., 2005 \\
\hline b) Others & (h) & 62.7 & Canakci et al., 2005 \\
\hline 3. Diesel & Liters $(\mathrm{l})$ & 47.8 & Ashkan et al., 2016 \\
\hline 4. Water & Cubic meter $\left(\mathrm{m}^{3}\right)$ & 1.02 & Ashkan et al., 2016 \\
\hline 5. Fertilizers & Kilogram $(\mathrm{kg})$ & & Rafiee et al., 2010 \\
\hline a) Nitrogen $(\mathrm{N})$ & & 66.14 & Rafiee et al., 2010 \\
\hline b) Phosphate $\left(\mathrm{P}_{2} \mathrm{O}_{5}\right)$ & & 12.44 & Rafiee et al., 2010 \\
\hline c) Potassium $\left(\mathrm{K}_{2} \mathrm{O}\right)$ & & 11.15 & Rafiee et al., 2010 \\
\hline d) Farmyard manure & $(\mathrm{kg})$ & 0.30 & \\
\hline 6. Chemicals & $(\mathrm{l})$ & & Erdal et al., 2007 \\
\hline a) Insecticides & $(\mathrm{l})$ & 101.20 & Erdal et al., 2007 \\
\hline b) Weedicides & $(\mathrm{l})$ & 25 & Moraditochaee, 2012 \\
\hline 7. Seed & $(\mathrm{kg})$ & & Moraditochaee, 2012 \\
\hline Outputs & & & \\
\hline 1. Tobacco yield & $(\mathrm{kg})$ & & \\
\hline
\end{tabular}

Source: own

their respective energy equivalents (MJ/Unit) as presented in Tab. 1.

All the physical inputs and output were converted into energy mega joules per hectare $\left(\mathrm{MJ} / \mathrm{ha}^{-1}\right)$ by simply multiplying the inputs with their respective coefficients of energy equivalents as given in Tab. 1. However, the energy inputs for farm machinery used in tobacco production was calculated by using the method adopted by Kitani and Jungbluth (1999) as given in formula (2):

$$
E_{M}=\frac{w \times E \times t}{T}
$$

Whereas $E_{M}$ is energy coefficient $\mathrm{MJ} / \mathrm{ha}^{-1}$ for per hour use of farm machinery, $w$ represents the machine weight in $\mathrm{kg}, t$ shows machine work time in hours, $E$ denotes the production energy in $\mathrm{MJ} /$ hour of the farm machines as given in Tab. 1, and $T$ is the machines economic lifetime (hours). Whereas Tab. 2 shows the total energy equivalents $\left(\mathrm{MJ} / \mathrm{ha}^{-1}\right)$ for each machine that

\section{Tab. 2: Machinery used and energy equivalents for tobacco production}

\begin{tabular}{l|c|c|c|c}
\multicolumn{1}{c|}{ Machine } & Weight $\mathbf{( k g )}$ & Lifetime $(\mathbf{h})$ & Usage (h/ha-1) & Total energy equivalents (MJ/ha-1) \\
\hline Tractor & 3,000 & 10,000 & 18.70 & 525.1 \\
\hline Cultivator & 500 & 2,500 & 3.93 & 49.28 \\
\hline Disk harrow & 575 & 2,500 & 4.65 & 67.05 \\
\hline Trailer & 750 & 5,000 & 5.41 & 50.88 \\
\hline Sprayer & 400 & 1,200 & 4.71 & 98.43 \\
\hline
\end{tabular}


were calculated by using formula (2) following Abbas et al. (2018b) and Mousavi-Avval et al. (2011a).

\subsection{Data Envelopment Analysis Approach}

Data Envelopment Analysis technique is a nonparametric method to calculate the relative efficiency of each entity in the sample and ranks decision-making units according to their efficiency scores. Moreover, the DEA does not require any assumptions to set a frontier between inputs and outputs (Seiford \& Thrall, 1990). The current study used DEA to optimize energy consumption in tobacco production and to rank efficient and inefficient DMUs.

Farrell (1957) introduced a new method to measure efficiency and production function at the micro-level by splitting economic efficiency into technical and allocative efficiency. The author presented a piecewise linear development of the data as the conservation estimate the production function, which envelopes observation points as closely as possible, which was estimated by solving a system of linear formulas. This model had a drawback that it was designed to calculate efficiency for a single input and output frontier (Abbas et al., 2018a).

DEA basic has two renowned models called CCR and BCC. Charnes et al. (1978) introduced Charnes, Cooper and Rhodes (CCR) that was ensemble to calculate multiple inputs and multiple output ratio and works on the assumption of constant return to scale, on the other side Banker et al. (1984) Banker, Cooper and Charnes (BCC) presented the $\mathrm{BCC}$ model that is also called a variable return to scale model, that works on the assumption of a variable return to scale. Infact we have more control over inputs instead of the outputs, therefore we preferred an input-oriented model (Pishgar-Komleh et al., 2020; Yang et al., 2020).

Efficiency in the DEA model can be optimized either by reducing inputs to an optimal level by keeping the output constant or by optimizing the output level by keeping the inputs constant. The former is also called input-oriented model while the latter is known as an output-oriented model. Choosing a suitable model from the above two depends upon the objectives of the research and the data characteristics (Zhou et al., 2008). Most of the agriculture-related studies use the input-oriented model because growers can only control the inputs and not the outputs (Pahlavan et al., 2012). Furthermore, The DEA input-oriented technique works on two basic assumptions; (i) contact return to scale, (ii) variable return to scale. Coelli et al. (2005) suggested that DEA-CCR is more suitable when firms are operating at the optimum level. But due to many constraints, such as farm size, financial crisis, credit facility, inputs availability, makes it impossible for the farmers in Pakistan. Therefore, to mitigate these difficulties, Banker et al. (1984) presented the DEA-BCC method. Considering the objective and nature of the study, the current study applies DEA inputoriented CCR, BCC, and Super efficiency approaches to analyze the data using MaxDEA and DEA-Solver-LV (V8) packages. Technical efficiency (TE), scale efficiency (SC), and pure technical efficiency (PTE) and super efficiency are mathematically expressed below in detail.

\section{Technical Efficiency}

The technical efficiency is defined as the ratio of the weighted sum of outputs to the sum of weighted inputs (Cooper et al., 2006). The value of $T E$ can be between 0 to 1 , DMU with $T E$ value one is efficient, and DMU with $T E$ value lower than one is inefficient and can become efficient by reducing inputs up to optimum level. Technical efficiency can be expressed mathematically as presented in formula (3) (Mousavi-Avval et al., 2011b; Wei et al., 2020b).

$$
T E_{j}=\frac{u_{1} y_{1 j}+u_{2} y_{2 j}+\cdots+u_{n} y_{n j}}{v_{1} x_{1 j}+v_{2} x_{2 j}+\cdots+v_{m} x_{m j}}=\frac{\sum_{r=1}^{n} u_{r} y_{r j}}{\sum_{s=1}^{m} v_{s} x_{s j}}
$$

where $T E_{J}$ represents the technical efficiency of DMU, $y$ shows the amount of $n^{\text {th }}$ output, $x_{s}$ shows the amount of $m^{\text {th }}$ input, $u_{r}$ is the energy coefficient of output $n, v_{s}$ is the energy coefficient for $m^{\text {th }}$ input, $j$ is $j^{\text {th }}$ DMUs $(j=1,2,3, \ldots k), r$ represents the number of outputs $(r=1,2,3, \ldots n)$ and $s$ is the number of inputs $(s=1,2,3, \ldots m)$. Linear programming (LP) was used to solve this formula, which was introduced by Charnes et al. (1978):

$$
\begin{aligned}
& \text { Maximize } \theta=\sum_{r=1}^{n} u_{r} y_{r j} \\
& \text { Subject to } \sum_{r=1}^{n} u_{r} y_{r j}-\sum_{s=1}^{m} v_{s} x_{s j} \leq 0 \\
& \qquad \sum_{s=1}^{m} v_{s} x_{s j}=1 \\
& (j=1,2, \ldots, k) \quad u_{r} \geq 0, \quad v_{s} \geq 0
\end{aligned}
$$


where $\theta$ represents technical efficiency and $j$ is the $j^{\text {th }}$ DMU. The given model is DEA-CCR model, also named as linear program model. This model assumes that the efficiency is not affected by the operational scale of DMUs, which means small farmers can be equally efficient to the big farmers in the production process (Mobtaker et al., 2012).

\section{Pure Technical Efficiency}

Pure technical efficiency can be estimated by using DEA-BCC approach, which is a variable return to scale model. Scale efficiency and technical efficiency can be separated using pure technical efficiency. This model compares efficient and inefficient producers of the same scale, and it is solved by the dual linear program (DPL), mathematically it can be expressed as in below given formulas (Mobtaker et al., 2012):

$$
\begin{aligned}
& \text { Maximize } Z=u y_{j}-u_{j} \\
& \text { subject to }=v x_{j}=1 \\
& v X+u Y-u_{0} e \leq 0 \\
& v \geq 0, \quad u \geq 0, \quad u_{0}
\end{aligned}
$$

where $x_{j}$ and $y_{j}$ are representing inputs and output of $\mathrm{DMUj} j^{\text {th }}$, weight matrices are represented by $v$ and $u$ for inputs and outputs respectively, corresponding input and output matrix is denoted by $X$ and $Y$, whereas $u_{j}$ is scaler and sign free.

\section{Scale Efficiency}

Two main causes of inefficiency are unsuitable scale and inadequate operations of DMU. Technical efficiency can be estimated by using the CCR model while PTE can be obtained from the BCC model (Khoshnevisan et al., 2013); whereas scale efficiency is defined as the ratio of technical efficiency to pure technical efficiency of the DMU, and it can be calculated by formula (10) as presented by Banker et al. (1984):

$$
\text { Scale Efficiency }=\frac{\text { Technical efficiency }}{\text { Pure Technical Efficency }}
$$

\section{Radial Super Efficiency}

Determination of the efficient DMUs remained the topic of keen interest for many researchers. DEA models CCR and BCC are used to find the efficient and inefficient DMUs considering the efficiency score one or less than one, respectively. But, there are often more than one DMUs with an efficiency score of one. Thus, the DEA super-efficiency model is used to rank and compare the most efficient DMUs in the sample. Many radial and none radial super-efficiency models had been introduced to find the most efficient DMUs, such as Tone (2001) introduced slacked based non-radial super-efficiency model. In this model DMUs with efficiency value higher than one are considered as efficient, the larger score will make DMU more superior than others in the sample. Considering the objective and the nature of the data, the present study will use the radial DEA input-oriented CCR superefficiency model introduced by Andersen and Petersen (1993) as mathematically expressed below:

$$
\begin{aligned}
& \text { [Super CCR.I] } \quad \theta^{*}=\text { Minimize } \theta_{0} \\
& \text { Subject to } \theta x_{0}=\sum_{j=1, j \neq 0}^{n} \lambda_{j} x_{j}+s^{-} \\
& y_{0}=\sum_{j=1, j \neq 0}^{n} \lambda_{j} y_{j}-s^{+} \\
& \lambda \geq 0, \quad s^{-} \geq 0, \quad s^{+} \geq 0
\end{aligned}
$$

The objective function in formulas (11)-(13) is minimization as we argued that in order to reach best frontier the slacks should be minimum. The minimization of slack is our target in objective function. Whereas $s^{-}$and $s^{+}$indicates the inputs and outputs slacks, respectively, for efficient DMUs the $\left(y_{0}, x_{0}\right), \theta^{*}$ is not less than unity and this value represents the super efficiency value. Whereas $j$ shows $D M U_{j}(j=1,2, \ldots, k), x_{j}=(1,2, \ldots, m)$ and $y_{j}=(1,2, \ldots, n)$ represents the inputs and outputs of $D M U_{j}$.

\section{Energy Saving Targets Ratio (ESTR)}

ESTR is defined as the ratio of energy-saving targets to actual energy inputs. ESTR is a useful technique to differentiate efficient and inefficient farmers, and energy use inefficiency for each DMU can be specified using ESTR. Mousavi-Avval et al. (2011b) and Abbas et al. (2018b) also used Energy saving targets ratio to suggest energy savings for different crops. ESTR can be calculated by the formula given in formula (14) (Hu \& Kao, 2007). 
$\operatorname{ESTR}(\%)=\frac{(\text { Energy Saving Target })}{(\text { Actual Energy Inputs })} \times 100$

where the energy-saving target is the total energy that can be saved without compromising the output level. The value of ESTR can lie between zero and hundred, DMU with ESTR value zero implies that DMU is fully efficient and no more energy can be reduced, whereas any value higher than zero indicates inefficient energy usage and indicates that DMU has energy-saving potential keeping output constant.

\section{Results and Discussions \\ 2.1 Energy Input-output Analysis for Tobacco Production}

The amount of physical inputs, output, energy equivalents, and standard deviations are given in Tab. 3. The average tobacco yield was calculated to be $3,871.23$ kilograms per hectare $\left(\mathrm{kg} / \mathrm{ha}^{-1}\right)$. The consumption of inputs, such as human labor, farmyard manure, and the seed, was calculated as $164.27 \mathrm{~h} / \mathrm{ha}^{-1}, 1,459.12 \mathrm{~kg} / \mathrm{ha}^{-1}$ and
$3.16 \mathrm{~kg} / \mathrm{ha}^{-1}$ respectively. The amount of chemical fertilizers, mainly nitrogen, phosphate, and potassium were $512.66 \mathrm{~kg} / \mathrm{ha}^{-1}, 200.12 \mathrm{~kg} / \mathrm{ha}^{-1}$, and $51.18 \mathrm{~kg} / \mathrm{ha}^{-1}$. Diesel, insecticide, and pesticide were consumed as given in Tab. 3 were 120.93 liters per hectares $\mathrm{l} / \mathrm{ha}^{-1}, 6.25 \mathrm{l} / \mathrm{ha}^{-1}$, and $3.49 \mathrm{l} / \mathrm{ha}^{-1}$. Water for irrigation was calculated to be $6,724.98 \mathrm{~m}^{3} / \mathrm{ha}^{-1}$, whereas machine hours and energy equivalents for each machine are already given in Tab. 2 .

The physical inputs and outputs were converted into energy equivalents $\mathrm{MJ} / \mathrm{ha}^{-1}$. The results in Tab. 3 revealed that total energy required in tobacco production was $52,703.58$ $\mathrm{MJ} / \mathrm{ha}^{-1}$, with the highest share of nitrogen calculated to be $33,908.40 \mathrm{MJ} / \mathrm{ha}^{-1}$ followed

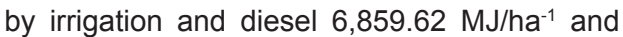
$5,780.60 \mathrm{MJ} / \mathrm{ha}^{-1}$ respectively. Abbas et al. (2018a) investigated energy use efficiency for corn production in Pakistan and reported that $30,969.47 \mathrm{MJ} / \mathrm{ha}^{-1}$ energy input was required in corn production. Furthermore, it was also noted that nitrogen has the highest share with $14,760.27 \mathrm{MJ} / \mathrm{ha}^{-1}$ of energy followed by

\section{Tab. 3: Average inputs, the output used for tobacco production and energy equivalents}

\begin{tabular}{|c|c|c|c|}
\hline Inputs \& outputs & Quantity (unit/ha-1) & Total energy (MJ/ha-1) & St. dev.* \\
\hline \multicolumn{4}{|l|}{ Inputs } \\
\hline 1. Human labor $(\mathrm{h})$ & 164.27 & 321.97 & 35.529 \\
\hline 2. Machinery $(\mathrm{h})$ & & 790.81 & \\
\hline 3. Diesel (I) & 120.93 & $5,780.60$ & 629.14 \\
\hline 4. Water $\left(m^{3}\right)$ & $6,724.98$ & $6,859.62$ & $1,046.90$ \\
\hline \multicolumn{4}{|l|}{ 5. Fertilizers (kg) } \\
\hline a) Nitrogen $(\mathrm{N})$ & 512.66 & $33,908.40$ & $11,675.15$ \\
\hline b) Phosphate $\left(\mathrm{P}_{2} \mathrm{O}_{5}\right)$ & 200.12 & $2,489.65$ & 861.00 \\
\hline c) Potassium $\left(\mathrm{K}_{2} \mathrm{O}\right)$ & 51.18 & 570.72 & 799.863 \\
\hline d) Farmyard manure & $1,459.12$ & 437.74 & 675.005 \\
\hline \multicolumn{4}{|l|}{ 6. Chemicals (I) } \\
\hline a) Insecticides & 6.25 & 632.32 & 275.69 \\
\hline b) Weedicides & 3.49 & 832.59 & 394.99 \\
\hline 7. Seed $(\mathrm{kg})$ & 3.16 & 79.16 & 28.49 \\
\hline \multicolumn{4}{|l|}{ Outputs } \\
\hline 1. Tobacco yield $(\mathrm{kg})$ & $3,871.233$ & $3,097.05$ & 475.39 \\
\hline Total energy output & & $52,703.58$ & \\
\hline
\end{tabular}


Tab. 4: Tobacco farmers average, maximum and minimum efficiencies

\begin{tabular}{l|c|c|c|c}
\multicolumn{1}{c|}{ Particular } & Average & Maximum & Minimum & St. dev. \\
\hline Technical efficiency & 0.902 & 1 & 0.633 & 0.081 \\
\hline Pure technical efficiency & 0.961 & 1 & 0.82 & 0.048 \\
\hline Scale efficiency & 0.938 & 1 & 0.724 & 0.067 \\
\hline
\end{tabular}

irrigation and diesel with 6,333.87 $\mathrm{MJ} / \mathrm{ha}^{-1}$ and 5,141.40 $\mathrm{MJ} / \mathrm{ha}^{-1}$ respectively, implies that nitrogen, irrigation, and diesel were the key energy inputs.

\subsection{Efficiency Estimation}

Technical, pure technical and scale efficiency of the producer was investigated using DEA - CCR and BCC approach. The results given in Tab. 4 indicate that average technical, pure technical and scale efficiency of the farmers were $0.902,0.961$, and 0.938 , respectively. The maximum technical efficiency calculated was 1.00 , and the minimum was 0.633 , with a standard deviation of 0.081 . Pure technical efficiency score remained between 1.00 and 0.82 . Whereas for scale efficiency maximum value was calculated as 1.00 and minimum score was 0.724 with a standard deviation of 0.067 . A large variation in technical efficiency score of producers implies that producers have technical inefficiency, for instance, the farmers were not applying the optimum amount of inputs at the right time and in proper way (Mohammadi et al., 2011).

Efficiency scores obtained from DEA-CCR and BCC for all three efficiencies are presented in Fig. 1. The results indicate that the majority of the farmers are working at an optimal level or near it. The results revealed that $45.24 \%$ of farmers, i.e., 95 out of total 210 , have a pure efficiency score of 1.00 . Whereas technical efficiency of 45 farmers was calculated to be 1.00 , that indicates that $21.42 \%$ of farmers are said to be globally efficient farmers. However, the remaining 40 farmers are said to be locally efficient due to some reasons or the other such as scale size. The rest of the 47 farmers have scale efficiency score of 1.00 . On the other hand, the majority of the inefficient farmers are also close to the efficient score, pure technical efficiency score of 83 farmers lies between 0.90 to 0.99 , and 32 farmers got a pure technical score between 0.80 to 0.89 ranges. These results are similar to the study conducted by Mohammadi et al. (2011) who applied DEA

\section{Fig. 1: Efficiency distribution of tobacco farmers}

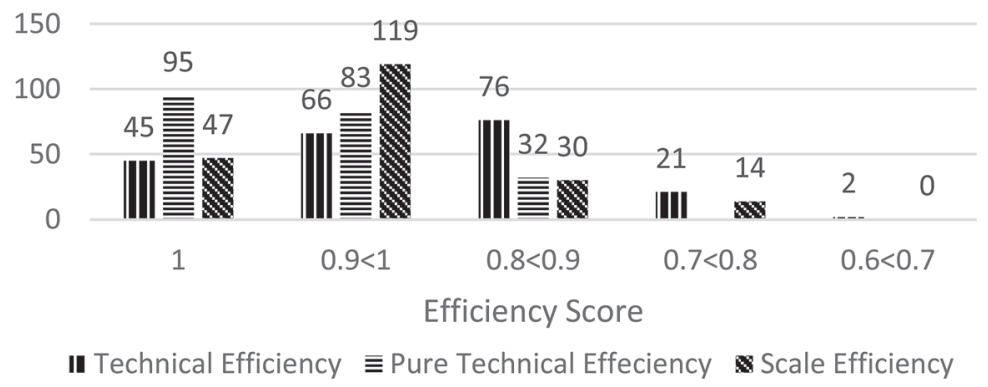




\begin{tabular}{c|c|c|c|c|c}
\hline Ranks & Farmer no. & Score & Ranks & Farmer no. & Score \\
\hline 1 & 113 & 1.697 & 6 & 112 & 1.038 \\
\hline 2 & 175 & 1.049 & 7 & 9 & 1.036 \\
\hline 3 & 96 & 1.048 & 8 & 201 & 1.026 \\
\hline 4 & 161 & 1.045 & 9 & 8 & 1.020 \\
\hline 5 & 89 & 1.040 & 10 & 71 & 1.014 \\
\hline
\end{tabular}

model to analyze energy efficiency in kiwi production; calculated technical, pure technical and scale efficiency score to be 0.94, 0.99 and 0.95 respectively. Mousavi-Avval et al. (2011b) reported technical, pure technical and scale efficiency to be $0.85,0.92$ and 0.93 respectively in soybean production in Iran.

\subsection{Ranking Farmers by Radial Super-efficiency Approach}

Super efficiency, benchmarking, and cross efficiency methods can be used to identify and rank the best performers among the efficient ones. Plenty of studies has already been conducted to rank efficient farmers using different techniques such as; Mousavi-Avval et al. (2011a) and Pahlavan et al. (2012) used benchmarking method to rank the efficient farmers, whereas Mousavi-Avval et al. (2011b) ranked efficient farmers by applying cross efficiency approach. This study identified and ranked 10 most efficient farmers using DEA super efficiency constant return to scale. The results in Tab. 5 indices that DMU 113 is the best farmers in the sample and has a super efficiency score of 1.697.

The farmer with the highest score in the super-efficiency model is considered to be the most efficient, and higher efficiency score makes the farmers more superior among others in the sample. Based on cited literature, no study could be found using DEA super efficiency model in the Pakistan context, especially in agricultural research.

\section{Tab. 6: Physical inputs and output comparison among efficient and inefficient farmers}

\begin{tabular}{|c|c|c|c|}
\hline Particulars (units) & (A) Efficient farmers & $\begin{array}{l}\text { (B) Inefficient } \\
\text { farmers }\end{array}$ & $\begin{array}{l}\text { (\%) Difference } \\
(B-A) \times 100 / B\end{array}$ \\
\hline \multicolumn{4}{|l|}{ Inputs } \\
\hline 1. Human labor $(\mathrm{h})$ & 142 & 154 & 7.79 \\
\hline 2. Machinery (h) & 34 & 36 & 5.5 \\
\hline 3. Diesel (I) & 109 & 125 & 12.8 \\
\hline 4. Water $\left(\mathrm{m}^{3}\right)$ & 5,914 & 6,626 & 10.47 \\
\hline 5. Fertilizers (kg) & 911 & 1,918 & 52.5 \\
\hline 6. Chemicals (I) & 4 & 12 & 66.5 \\
\hline 7. Seed $(\mathrm{kg})$ & 3 & 3 & 0 \\
\hline \multicolumn{4}{|l|}{ Outputs } \\
\hline 1. Tobacco yield $(\mathrm{kg})$ & 3,805 & 2,891 & -31.62 \\
\hline
\end{tabular}




\subsection{Comparing Consumption of Physical Inputs among Efficient and Inefficient Farmers}

Efficient and inefficient farmers were identified by using DEA super efficiency model. The results given in Tab. 6 implies the average amount of physical inputs consumed and output gained by 15 most efficient and inefficient farmers. The findings divulged that all efficient farmers not only consumed less amount of physical inputs in the production process but also obtained higher yield than inefficient farmers. It can also be observed in the results given in Tab. 6 that among inefficient farmers, the use of fertilizers and other chemical was the highest $52.5 \%$ and $66.5 \%$, followed by diesel and irrigation. Efficient farmers have $31.62 \%$ higher output than inefficient farmers. Different studies also reported that inefficient farmers were using a high amount of physical inputs with less obtained outputs (Mobtaker et al., 2012).

\subsection{Optimum Energy Required and Saving Targets}

The results obtained from the DEA BCC model were used to suggest the optimal amount of energy required and potential energy savings in tobacco production. The results in Tab. 7 indicated that optimal energy required in tobacco production was calculated to be 51,585.89 $\mathrm{MJ} / \mathrm{ha}^{-1}$ and results also revealed that $7,121.66 \mathrm{MJ} / \mathrm{ha}^{-1}$ of energy can be saved if farmers adopt best management practices. It is also evident from the results that the optimum energy requirement for different inputs such as fertilizers, chemicals, diesel, irrigation, machinery, seed, and human labor is $33,968.78,1,135.97,5,256.12,6,859,996$, 71.20 and $298.90 \mathrm{MJ} / \mathrm{ha}^{-1}$ respectively.

The optimal energy requirements in the form of fertilizers and chemicals remained highest followed machine and diesel. Energy saving target ratio ESTR is also presented in Tab. 7, which indicated that $18.03 \%$ and $11.96 \%$ energy could be saved from chemicals and fertilizers in tobacco production. In addition to that, ESTR also shows that in total, $13.83 \%$ energy can be saved by adopting best management practices.

Abbas et al. (2018a) suggest that total $17.11 \%$ energy could be saved in corn production in Pakistan; energy consumed in the form of chemicals, fertilizers, irrigation, and farm machinery had the highest potential of energy savings. Chauhan et al. (2006) carried out a study to investigate energy efficiency in paddy production in India and suggest that $11.6 \%$ energy consumed in the form of inputs could be saved in paddy production.

\subsection{Advising Optimal Energy Requirement Level for Inefficient Farmers}

Agricultural production follows the principle of diminishing marginal productivity. As in the present study land used by farmers' remains

Tab. 7: Optimum energy requirements and energy savings for tobacco farmer

\begin{tabular}{|c|c|c|c|}
\hline Particulars (units) & $\begin{array}{l}\text { Optimum energy } \\
\text { requirement } \\
\left(\mathrm{MJ} / \mathrm{ha}^{-1}\right)\end{array}$ & $\begin{array}{l}\text { Energy savings } \\
\left(\mathrm{MJ} / \mathrm{ha}^{-1}\right)\end{array}$ & ESTR (\%) \\
\hline 1. Human labor $(\mathrm{h})$ & 298.90 & 23.06 & 6.62 \\
\hline 2. Machinery (h) & 996 & 98 & 9.11 \\
\hline 3. Diesel (I) & $5,256.12$ & 524.47 & 8.56 \\
\hline 4. Water $\left(\mathrm{m}^{3}\right)$ & 6,859 & 501.68 & 6.58 \\
\hline 5. Fertilizers $(\mathrm{kg})$ & $36,968.78$ & $5,640.56$ & 11.96 \\
\hline 6. Chemicals (I) & $1,135.97$ & 328.94 & 18.03 \\
\hline 7. Seed $(k g)$ & 71.20 & 7.95 & 7.99 \\
\hline Total & $51,585.89$ & $7,121.66$ & 13.83 \\
\hline
\end{tabular}


fixed during the production period, therefore, with the continuous increase in other inputs while keeping the land fixed will not increase the output after a certain level. Concluding that for sustainable agriculture production it is very important to optimize the level of inputs instead of maximization of agricultural inputs. Thus, Tab. A2 in the Appendix explains the actual and the optimum energy input required for farmers without affecting the output.

Farmers with pure technical efficiency score less than 1.00 are currently inefficient farmers and applying the undesired amount of energy inputs. So, it is essential to recommend optimal energy requirements to the inefficient farmers. On the bases of the results obtained from the BCC model, 115 farmers were found to be using more inputs than the optimal level. The results given in Tab. A2 indicate the amount of energy inputs being used by inefficient farmers and in next half optimum amount of the inputs is recommended. ESTR for each farmer given in the last column of Tab. A2 indicates the percentage of energy inputs that each inefficient farmer can save respectively. Farmer no. 115 has ESTR $46 \%$, which is considered to be worst among the inefficient farmers and could save $46 \%$ of energy by applying the optimal amount of energy inputs in tobacco production.

The results indice that in tobacco production farmers are applying the undesired amount of energy inputs in form for fertilizers, chemicals, irrigation, and diesel due to mismanagement and lack of education, technical training, and knowledge. There is a great potential to reduce production cost and environmental degradation by applying the optimal amount of energy inputs required for crop production. Technical training, extension services, and proper education should be provided to the farmers. In this matter, the government should involve agriculture institutes to deploy agricultural graduates as internee to guide farmers. Furthermore, NGOs and private sector organizations such as (fertilizers, seed, and chemical companies) should provide technical and smart training to the farmers to adopt best management practices. Extension department should launch some awareness program to apply best management practice and apply optimum energy inputs to reduce cost and save the environment. The government should initiate some technical training school at the local level for short courses to train farmers about the application of chemical and fertilizers; and the use of lasts technology such as machines and irrigation techniques.

\section{Conclusion}

The current study was conducted to investigate the energy efficiency in tobacco production in Pakistan. Data Envelopment Analysis, CCR, $B C C$, and super-efficiency models were applied to find the technical, pure technical efficiency and raking the superior farmers, respectively. The results of the study indicated that tobacco crop is energy extensive crop and the huge amount of energy inputs in the form of fertilizers, chemicals, irrigation, and diesel is required. The findings also divulged that chemicals, fertilizers, irrigation, and diesel had the highest potential to save energy. Overall, $13 \%$ of the energy could be saved if all tobacco growers in the sample were operating at the full efficient level. Adopting an optimal level of energy inputs can make tobacco farmers more competitive in the region with a reduction in the production cost. Technical training to adopt best management practices and applying the required level of energy inputs can improve energy efficiency. Ending with the note; that DEA super efficiency technique was beneficial to identify and rank the energy inefficiency in tobacco production and to suggest required energy levels in the region.

\section{References}

Abbas, A., Yang, M., Yousaf, K., Ahmad, M., Elahi, E., \& Iqbal, T. (2018a). Improving energy use efficiency of corn production by using Data Envelopment Analysis (a non-parametric approach). Fresenius Environmental Bulletin, 27(7), 4725-4733.

Abbas, A., Yang, M., Yousaf, K., Khan, K. A., Iqbal, T., \& Hassan, S. G. (2018b). Comparative analysis of energy use efficiency in food grain production systems of Pakistan. Fresenius Environmental Bulletin, 27(2), 1053-1059.

Afzal, N., \& Ahmad, S. (2009) Agricultural input use efficiency in Pakistan: Key issues and reform areas. Managing Natural Resources for Sustaining Future Agriculture Research Briefings, 1(3), 1-12.

Alam, M. S., Alam, M., \& Islam, K. (2005). Energy flow in agriculture: Bangladesh. American Journal of Environmental Sciences, 1(3), 213-220. https://doi.org/10.3844/ ajessp.2005.213.220 
Alimagham, S. M., Soltani, A., Zeinali, E., \& Kazemi, H. (2017). Energy flow analysis and estimation of greenhouse gases (GHG) emissions in different scenarios of soybean production (Case study: Gorgan region, Iran). Journal of Cleaner Production, 149, 621-628. https://doi.org/10.1016/j.jclepro.2017.02.118

Andersen, P., \& Petersen, N. C. (1993). A Procedure for Ranking Efficient Units in Data Envelopment Analysis. Management Science, 39(10), 1261-1264. Retrieved from https://www. jstor.org/stable/2632964

Andrianov, V., Borisjuk, N., Pogrebnyak, N., Brinker, A., Dixon, J., Spitsin, S., Flynn, J., Matyszczuk, P., Andryszak, K., \& Laurelli, M. (2010). Tobacco as a production platform for biofuel: overexpression of Arabidopsis DGAT and LEC2 genes increases accumulation and shifts the composition of lipids in green biomass. Plant Biotechnology Journal, 8(3), 277-287. https://doi.org/10.1111/j.14677652.2009.00458.x

Ashkan, N. P., Hosseinzadeh-Bandbafha, H., Qasemi-Kordkheili, P., Kouchaki-Penchah, H., \& Riahi-Dorcheh, F. (2016). Applying optimization techniques to improve of energy efficiency and GHG (greenhouse gas) emissions of wheat production. Energy, 103, 672-678. https://doi.org/10.1016/j.energy.2016.03.003

Banker, R. D., Charnes, A., \& Cooper, W. W. (1984). Some Models for Estimating Technical and Scale Inefficiencies in Data Envelopment Analysis. Management Science, 30(9), 10781092. https://doi.org/10.1287/mnsc.30.9.1078

Baran, M., \& Gokdogan, O. (2015). Determination of energy input-output of Tobacco production in Turkey. American-Eurasian Journal of Agricultural and Environmental Sciences, 15(7), 1346-1350. https://doi. org/10.5829/idosi.aejaes.2015.15.7.12671

Board, P. T. (2018). Tobacco Statistical Bulletin. Ministry of Commerce, Government of Pakistan, Peshawar. Retrieved from https://ptb. gov.pk/

Boz, I. (2015). Adoption of innovations and best management practices by goat farmers in eastern Mediterranean Region of Turkey. Journal of Agricultural Extension and Rural Development, 7(7), 229-239. https://doi. org/10.5897/JAERD2014.0668

Canakci, M., Topakci, M., Akinci, I., \& Ozmerzi, A. (2005). Energy use pattern of some field crops and vegetable production: Case study for Antalya Region, Turkey. Energy Conversion and Management, 46(4), 655-666. https://doi. org/10.1016/j.enconman.2004.04.008

Charnes, A., Cooper, W. W., \& Rhodes, E. (1978). Measuring the efficiency of decision making units. European Journal of Operational Research, 2(6), 429-444. https://doi. org/10.1016/0377-2217(78)90138-8

Chauhan, N. S., Mohapatra, P. K. J., \& Pandey, K. P. (2006). Improving energy productivity in paddy production through benchmarking - An application of Data Envelopment Analysis. Energy Conversion and Management, 47(9-10), 1063-1085. https://doi.org/10.1016/j.enconman.2005. 07.004

Coelli, T. J., Rao, D. S. P., O'Donnell, C. J., \& Battese, G. E. (2005). An Introduction to Efficiency and Productivity Analysis. New York, NY: Springer Science \& Business Media. https:// www.springer.com/gp/book/9781461554936

Cooper, W. W., Seiford, L. M., \& Tone, K. (2006). Introduction to Data Envelopment Analysis and Its Uses - With DEA-Solver Software and References. New York, NY: Springer. https://www.springer.com/gp/book/ 9780387285801

Ebrahimi, R., \& Salehi, M. (2015). Investigation of $\mathrm{CO}_{2}$ emission reduction and improving energy use efficiency of button mushroom production using Data Envelopment Analysis. Journal of Cleaner Production, 103, 112-119. https://doi.org/10.1016/j. jclepro.2014.02.032

Erdal, G., Esengün, K., Erdal, H., \& Gündüz, O. (2007). Energy use and economical analysis of sugar beet production in Tokat province of Turkey. Energy, 32(1), 35-41. https://doi. org/10.1016/j.energy.2006.01.007

Farrell, M. J. (1957). The Measurement of Productive Efficiency. Journal of the Royal Statistical Society: Series A (General), 120(3), 253-281. https://doi.org/10.2307/2343100

GOP. (2018). Pakistan Economic Survey 2017-18. Finance Division, Economic Advisor's Wing: Islamabad, Pakistan. Retrieved from http://www.finance.gov.pk/survey_1718.html

Hatirli, S. A., Ozkan, B., \& Fert, C. (2005). An econometric analysis of energy inputoutput in Turkish agriculture. Renewable and Sustainable Energy Reviews, 9(6), 608-623. https://doi.org/10.1016/j.rser.2004.07.001

Hatirli, S. A., Ozkan, B., \& Fert, C. (2006). Energy inputs and crop yield relationship in greenhouse tomato production. Renewable 
Energy, 31(4), 427-438. https://doi. org/10.1016/j.renene.2005.04.007

Heidari, M., Omid, M., \& Akram, A. (2011). Using nonparametric analysis (DEA) for measuring technical efficiency in poultry farms. Brazilian Journal of Poultry Science, 13(4), 271-277. https://doi.org/10.1590/S1516635X2011000400009

Hu, J.-L., \& Kao, C.-H. (2007). Efficient energy-saving targets for APEC economies. Energy Policy, 35(1), 373-382. https://doi. org/10.1016/j.enpol.2005.11.032

Khoshnevisan, B., Rafiee, S., Omid, M., \& Mousazadeh, H. (2013). Applying Data Envelopment Analysis approach to improve energy efficiency and reduce GHG (greenhousegas) emission of wheat production. Energy, 58, 588-593. https://doi.org/10.1016/j. energy.2013.06.030

Kitani, O., \& Jungbluth, T. (1999). CIGR Handbook of Agricultural Engineering, Volume V: Energy and Biomass Engineering. Gainesville, FL: CIGR International Commission of Agricultural and Biosystems Engineering.

Kizilaslan, H. (2009). Input-output energy analysis of cherries production in Tokat Province of Turkey. Applied Energy, 86(7-8), 1354-1358. https://doi.org/10.1016/j.apenergy.2008.07.009

Kousar, R., Makhdum, M. S. A., Yaqoob, S., \& Saghir, A. (2006). Economics of energy use in cotton production on small farms in district Sahiwal, Punjab, Pakistan. Journal of Agriculture \& Social Science, 2(4), 219-221.

Kuhn, L., Balezentis, T., Hou, L., \& Wang, D. (2018). Technical and environmental efficiency of livestock farms in China: A slacks-based DEA approach. China Economic Review, 62, 101213. https://doi.org/10.1016/j.chieco.2018.08.009

Liu, K.-F. (2015). Application of DEA method in the evaluation of agriculture economic efficiency. Journal of Chemical and Pharmaceutical Research, 7(3), 997-1000. Retrieved from http://jocpr.com/vol7-iss3-2015/ JCPR-2015-7-3-997-1000.pdf

Loghmanpour-Zarini, R., \& AbediFirouzjaee, R. (2013). Energy and water use indexes for tobacco production under different irrigation systems in Iran. International Journal of Agriculture and Crop Sciences, 5(12), 1332-1339. Retrieved from https://docplayer. net/20346789-Energy-and-water-use-indexesfor-tobacco-production-under-differentirrigation-systems-in-iran.html

Mandal, K., Saha, K., Ghosh, P., Hati, K., \& Bandyopadhyay, K. (2002). Bioenergy and economic analysis of soybean-based crop production systems in central India. Biomass and Bioenergy, 23(5), 337-345. https://doi. org/10.1016/S0961-9534(02)00058-2

Mardani, M., \& Salarpour, M. (2015). Measuring technical efficiency of potato production in Iran using robust Data Envelopment Analysis. Information Processing in Agriculture, 2(1), 6-14. https://doi. org/10.1016/j.inpa.2015.01.002

Mobtaker, H. G., Akram, A., Keyhani, A., \& Mohammadi, A. (2012). Optimization of energy required for alfalfa production using Data Envelopment Analysis approach. Energy for Sustainable Development, 16(2), 242-248. https://doi.org/10.1016/j.esd.2012.02.001

Mohammadi, A., \& Omid, M. (2010). Economical analysis and relation between energy inputs and yield of greenhouse cucumber production in Iran. Applied Energy, 87(1), 191-196. https://doi.org/10.1016/j. apenergy.2009.07.021

Mohammadi, A., Rafiee, S., Mohtasebi, S. S., Mousavi-Avval, S. H., \& Rafiee, H. (2011). Energy efficiency improvement and input cost saving in kiwifruit production using Data Envelopment Analysis approach. Renewable Energy, 36(9), 2573-2579. https://doi. org/10.1016/j.renene.2010.10.036

Mohammadi, A., Tabatabaeefar, A., Shahin, S., Rafiee, S., \& Keyhani, A. (2008). Energy use and economical analysis of potato production in Iran a case study: Ardabil province. Energy Conversion and Management, 49(12), 3566-3570. https://doi.org/10.1016/j. enconman.2008.07.003

Moraditochaee, M. (2012). Study energy indices of tobacco production in north of Iran. Journal of Agricultural and Biological Science, 7(6), 462-465. Retrieved from http://www. arpnjournals.com/jabs/research_papers/ rp_2012/jabs_0612_418.pdf

Mousavi-Avval, H. S., Rafiee, S., Jafari, A., \& Mohammadi, A. (2011a). Improving energy use efficiency of canola production using Data Envelopment Analysis (DEA) approach. Energy, 36(5), 2765-2772. https://doi.org/10.1016/j. energy.2011.02.016

Mousavi-Avval, H. S., Rafiee, S., Jafari, A., \& Mohammadi, A. (2011b). Optimization of energy consumption for soybean production using Data Envelopment Analysis (DEA) approach. Applied Energy, 88(11), 3765-3772. https://doi.org/10.1016/j.apenergy.2011.04.021 
Nasiri, S. M., \& Singh, S. (2010). A comparative study of parametric and nonparametric energy use efficiency in paddy production. Journal of Agricultural Science and Technology, 12(4), 391-399. https://www.sid.ir/ en/journal/ViewPaper.aspx?id=180618

Ozkan, B., Kurklu, A., \& Akcaoz, H. (2004). An input-output energy analysis in greenhouse vegetable production: a case study for Antalya region of Turkey. Biomass and Bioenergy, 26(1), 89-95. https://doi.org/10.1016/S09619534(03)00080-1

Pahlavan, R., Omid, M., \& Akram, A. (2011) Energy use efficiency in greenhouse tomato production in Iran. Energy, 36(12), 6714-6719. https://doi.org/10.1016/j.energy.2011.10.038

Pahlavan, R., Omid, M., Rafiee, S., \& Mousavi-Avval, S. H. (2012). Optimization of energy consumption for rose production in Iran. Energy for Sustainable Development, 16(2), 236241. https://doi.org/10.1016/j.esd.2011.12.001

Pishgar-Komleh, S. H., Ghahderijani, M., \& Sefeedpari, P. (2012). Energy consumption and CO2 emissions analysis of potato production based on different farm size levels in Iran. Journal of Cleaner Production, 33, 183-191. https://doi.org/10.1016/j.jclepro.2012.04.008

Pishgar-Komleh, S. H., Zylowski, T., Rozakis, S., \& Kozyra, J. (2020). Efficiency under different methods for incorporating undesirable outputs in an LCA+DEA framework: A case study of winter wheat production in Poland. Journal of Environmental Management, 260, 110138. https://doi.org/10.1016/j.jenvman.2020.110138

Rafiee, S., Mousavi-Avval, S. H., \& Mohammadi, A. (2010). Modeling and sensitivity analysis of energy inputs for apple production in Iran. Energy, 35(8), 3301-3306. https://doi. org/10.1016/j.energy.2010.04.015

Seiford, L. M., \& Thrall, R. M. (1990). Recent developments in DEA: The mathematical programming approach to frontier analysis. Journal of Econometrics, 46(1-2), 7-38. https:// doi.org/10.1016/0304-4076(90)90045-U

Shahbandeh, M. (2020). Tobacco production worldwide 2018, by country. Statista. https://www.statista.com/statistics/261173/ leading-countries-in-tobacco-production/

Singh, G., Singh, S., \& Singh, J. (2004). Optimization of energy inputs for wheat crop in Punjab. Energy Conversion and Management, 45(3), 453-465. https://doi.org/10.1016/S01968904(03)00155-9
Singh, S., Mittal, J. P., Singh, M. P., \& Bakhshi, R. (1988). Energy-use patterns under various farming systems in Punjab. Applied Energy, 30(4), 261-268. https://doi. org/10.1016/0306-2619(88)90013-X

Thanassoulis, E. (1993). A comparison of regression analysis and Data Envelopment Analysis as alternative methods for performance assessments. Journal of the Operational Research Society, 44(11), 1129-1144. https:// doi.org/10.2307/2583874

Tone, K. (2001). A slacks-based measure of efficiency in Data Envelopment Analysis. European Journal of Operational Research, 130(3), 498-509. https://doi.org/10.1016/ S0377-2217(99)00407-5

Unakıtan, G., \& Aydın, B. (2018). A comparison of energy use efficiency and economic analysis of wheat and sunflower production in Turkey: A case study in Thrace Region. Energy, 149, 279-285. https://doi. org/10.1016/j.energy.2018.02.033

Wang, G., Lin, N., Zhou, X., Li, Z., \& Deng, $X$. (2018). Three-Stage Data Envelopment Analysis of Agricultural Water Use Efficiency: A Case Study of the Heine River Basin. Sustainability, 10(2), $568 . \quad$ https://doi. org/10.3390/su10020568

Wei, W., Mushtaq, Z., Ikram, A., Faisal, M., Wan-Li, Z., \& Ahmad, M. I. (2020a). Estimating the Economic Viability of Cotton Growers in Punjab Province, Pakistan. SAGE Open, 10(2), 2158244020929310. https://doi. org/10.1177\%2F2158244020929310

Wei, W., Mushtaq, Z., Faisal, M., \& Wan$\mathrm{Li}, \quad$ Z. (2020b). Estimating the economic and production efficiency of cotton growers in Southern Punjab, Pakistan. Custos e Agronegocio, 16(2), 2-21. Retrieved from http://www.custoseagronegocioonline.com.br/ numero2v16/OK\%201\%20cotton\%20english. pdf

Wei, W., Mushtaq, Z., Sharif, M., Zeng, X., Wan-Li, Z., \& Qaisrani, M. A. (2020c). Evaluating the coal rebound effect in energy intensive industries of China. Energy, 207, 118247. https://doi.org/10.1016/j.energy.2020.118247

Yang, M., Hou, Y., Ji, Q., \& Zhang, D. (2020). Assessment and optimization of provincial $\mathrm{CO} 2$ emission reduction scheme in China: An improved ZSG-DEA approach. Energy Economics, 91, 104931. https://doi. org/10.1016/j.eneco.2020.104931 
Zhang, X., Huang, G. H., Lin, Q., \& Yu, H. (2009). Petroleum-contaminated groundwater remediation systems design: A Data Envelopment Analysis based approach. Expert Systems with Applications, 36(3), 5666-5672. https://doi.org/10.1016/j.eswa.2008.06.136
Zhou, P., Ang, B. W., \& Poh, K. L. (2008). A survey of Data Envelopment Analysis in energy and environmental studies. European Journal of Operational Research, 189(1), 1-18. https://doi.org/10.1016/j.ejor.2007.04.042

\section{Appendix}

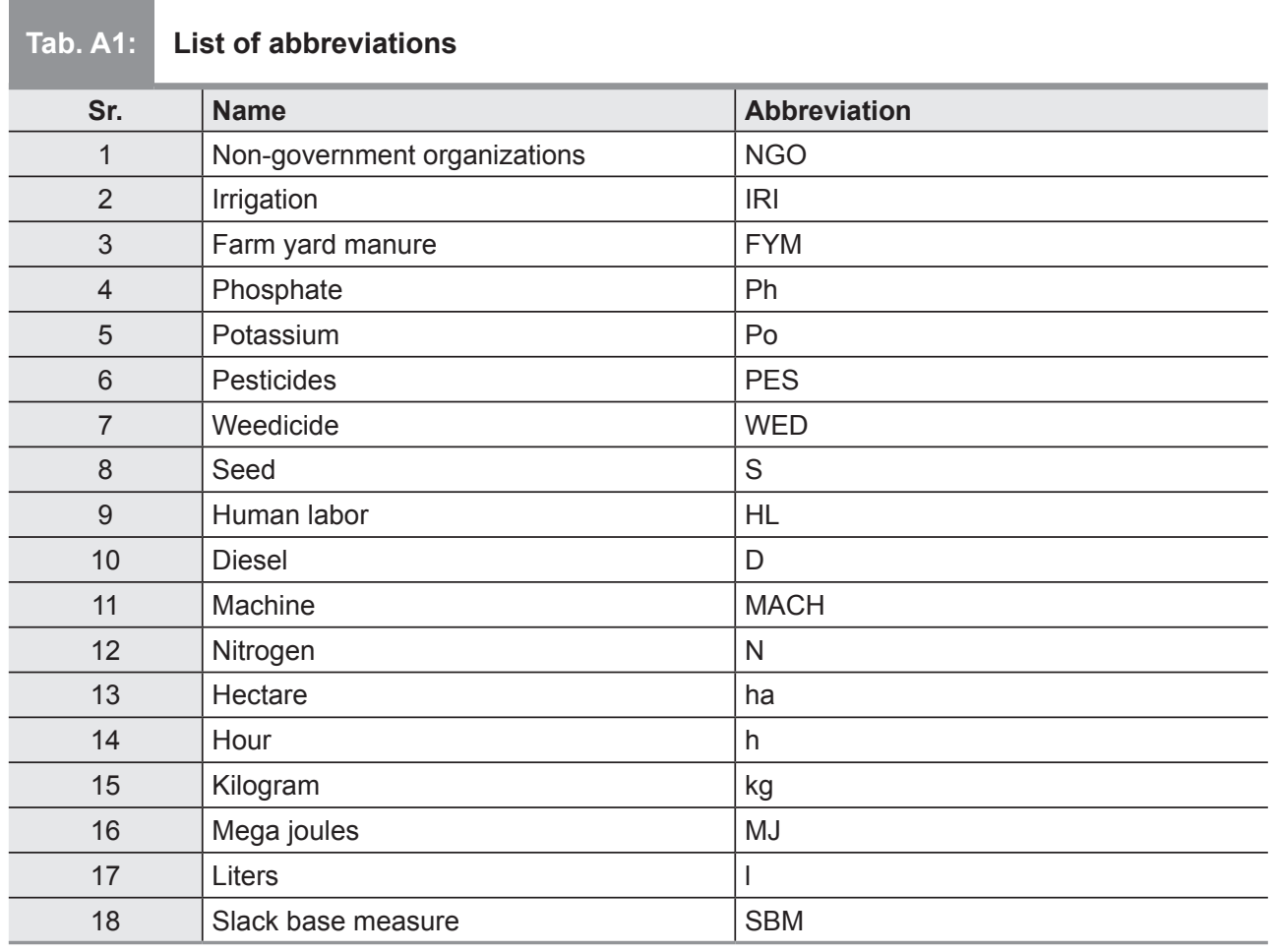




\section{Tab. A2: Actual energy consumption and optimal energy requirements $\mathrm{MJ} / \mathrm{ha}^{-1}$ - Part 1}

\begin{tabular}{|c|c|c|c|c|c|c|c|c|c|c|c|c|}
\hline \multicolumn{13}{|c|}{ Actual energy consumption (MJ/ha-1) } \\
\hline DMU & PTE & IRI & FYM & N & $\mathrm{Ph}$ & Po & PES & WED & S & HL & D & $\mathrm{MACH}$ \\
\hline 001 & 0.92 & 6,144 & 0 & 49,498 & 3,118 & 0 & 750 & 1,176 & 88 & 302 & 5,191 & 1,006 \\
\hline 002 & 0.89 & 7,370 & 712 & 50,011 & 3,197 & 0 & 1,000 & 588 & 49 & 325 & 5,723 & 1,110 \\
\hline 003 & 0.88 & 9,104 & 3,558 & 49,684 & 3,135 & 0 & 1,000 & 588 & 82 & 329 & 6,462 & 1,253 \\
\hline 004 & 0.92 & 6,720 & 1,779 & 33,177 & 3,120 & 0 & 750 & 588 & 93 & 300 & 5,866 & 1,137 \\
\hline 010 & 0.90 & 9,104 & 1,779 & 50,011 & 3,166 & 1,378 & 500 & 588 & 93 & 392 & 6,162 & 1,207 \\
\hline 012 & 0.93 & 8,562 & 1,334 & 41,513 & 3,135 & 1,378 & 750 & 588 & 77 & 380 & 5,808 & 1,137 \\
\hline 016 & 0.93 & 7,603 & 0 & 41,173 & 3,086 & 689 & 1,000 & 1,176 & 62 & 335 & 5,321 & 1,089 \\
\hline 021 & 0.90 & 7,370 & 1,779 & 49,439 & 1,614 & 0 & 1,250 & 1,176 & 62 & 320 & 5,443 & 1,114 \\
\hline 027 & 0.88 & 7,011 & 0 & 41,232 & 3,109 & 0 & 500 & 1,176 & 88 & 338 & 5,256 & 1,076 \\
\hline 029 & 0.88 & 7,184 & 0 & 49,653 & 3,133 & 0 & 500 & 588 & 88 & 330 & 5,346 & 1,094 \\
\hline 032 & 0.90 & 8,020 & 1,779 & 49,848 & 3,151 & 689 & 1,000 & 588 & 124 & 351 & 7,163 & 1,137 \\
\hline 041 & 0.90 & 7,470 & 342 & 40,934 & 3,092 & 0 & 750 & 1,176 & 95 & 308 & 6,356 & 1,009 \\
\hline 049 & 0.93 & 7,470 & 0 & 49,408 & 3,109 & 1,378 & 500 & 588 & 59 & 329 & 6,793 & 1,079 \\
\hline 051 & 0.92 & 6,156 & 0 & 24,842 & 3,105 & 0 & 1,000 & 588 & 99 & 343 & 5,585 & 1,010 \\
\hline 055 & 0.87 & 6,729 & 0 & 41,143 & 3,119 & 1,378 & 500 & 1,176 & 81 & 314 & 6,041 & 1,092 \\
\hline 058 & 0.86 & 7,630 & 0 & 33,177 & 3,120 & 0 & 750 & 1,176 & 93 & 358 & 5,677 & 1,026 \\
\hline 063 & 0.92 & 7,002 & 0 & 41,186 & 3,105 & 0 & 750 & 588 & 46 & 319 & 5,946 & 1,075 \\
\hline 067 & 0.89 & 6,153 & 0 & 41,079 & 3,098 & 0 & 1,000 & 1,470 & 83 & 353 & 5,967 & 1,079 \\
\hline 068 & 0.84 & 9,321 & 0 & 41,513 & 3,135 & 1,378 & 500 & 1,176 & 93 & 397 & 6,675 & 1,207 \\
\hline 072 & 0.86 & 7,197 & 0 & 49,684 & 3,135 & 689 & 500 & 588 & 93 & 371 & 5,558 & 1,096 \\
\hline 076 & 0.84 & 8,004 & 0 & 49,785 & 3,145 & 0 & 1,250 & 1,176 & 119 & 383 & 5,525 & 1,089 \\
\hline 077 & 0.87 & 7,197 & 890 & 41,186 & 3,105 & 0 & 750 & 1,176 & 93 & 326 & 5,558 & 1,096 \\
\hline 079 & 0.91 & 7,088 & 356 & 49,439 & 3,112 & 1,378 & 500 & 588 & 62 & 328 & 5,487 & 1,082 \\
\hline 084 & 0.92 & 7,011 & 0 & 41,326 & 3,118 & 0 & 750 & 588 & 53 & 327 & 5,457 & 1,076 \\
\hline 097 & 0.92 & 7,989 & 0 & 49,498 & 3,118 & 1,378 & 750 & 1,176 & 88 & 343 & 5,777 & 1,088 \\
\hline 099 & 0.92 & 7,170 & 0 & 49,345 & 3,086 & 689 & 750 & 1,176 & 62 & 332 & 5,785 & 1,089 \\
\hline 105 & 0.82 & 7,556 & 0 & 49,498 & 3,118 & 1,378 & 750 & 882 & 88 & 342 & 5,777 & 1,088 \\
\hline 106 & 0.92 & 6,144 & 0 & 49,498 & 3,118 & 0 & 750 & 1,176 & 88 & 302 & 5,345 & 1,006 \\
\hline 107 & 0.89 & 7,370 & 712 & 50,011 & 3,197 & 0 & 500 & 588 & 49 & 325 & 5,893 & 1,110 \\
\hline 108 & 0.87 & 9,104 & 3,558 & 49,684 & 3,135 & 0 & 750 & 1,470 & 82 & 329 & 6,654 & 1,253 \\
\hline 118 & 0.93 & 8,844 & 0 & 33,079 & 3,123 & 1,378 & 750 & 941 & 74 & 382 & 5,135 & 1,040 \\
\hline 121 & 0.92 & 7,603 & 0 & 41,173 & 3,086 & 689 & 750 & 1,176 & 62 & 335 & 5,377 & 1,089 \\
\hline 123 & 0.87 & 6,590 & 1,067 & 41,513 & 3,135 & 0 & 1,000 & 1,764 & 86 & 383 & 5,203 & 1,054 \\
\hline 124 & 0.89 & 8,064 & 890 & 49,357 & 3,120 & 1,378 & 750 & 1,176 & 93 & 371 & 7,087 & 1,096 \\
\hline 125 & 0.91 & 6,142 & 0 & 32,778 & 3,081 & 2,755 & 500 & 588 & 103 & 307 & 6,509 & 1,006 \\
\hline 126 & 0.88 & 7,370 & 1,779 & 49,439 & 1,614 & 0 & 750 & 1,176 & 62 & 320 & 6,240 & 1,114 \\
\hline 132 & 0.83 & 7,011 & 0 & 41,232 & 3,109 & 0 & 750 & 1,176 & 88 & 338 & 6,025 & 1,076 \\
\hline 134 & 0.84 & 7,184 & 0 & 49,653 & 3,133 & 0 & 500 & 1,176 & 88 & 330 & 6,129 & 1,094 \\
\hline 137 & 0.90 & 8,020 & 1,779 & 49,848 & 3,151 & 689 & 750 & 588 & 124 & 351 & 6,369 & 1,137 \\
\hline 138 & 0.90 & 8,237 & 1,779 & 49,575 & 3,125 & 689 & 750 & 1,176 & 185 & 336 & 6,499 & 1,160 \\
\hline 140 & 0.91 & 6,503 & 890 & 33,232 & 3,125 & 1,378 & 750 & 1,176 & 103 & 308 & 5,851 & 1,045 \\
\hline 146 & 0.91 & 7,470 & 342 & 40,934 & 3,092 & 0 & 1,000 & 882 & 166 & 308 & 5,652 & 1,009 \\
\hline 154 & 0.93 & 7,470 & 0 & 49,408 & 3,109 & 1,378 & 750 & 1,176 & 59 & 329 & 6,426 & 1,079 \\
\hline 156 & 0.93 & 6,156 & 0 & 24,842 & 3,105 & 0 & 500 & 588 & 99 & 343 & 6,015 & 1,010 \\
\hline 160 & 0.87 & 6,729 & 0 & 41,143 & 3,119 & 1,378 & 875 & 882 & 81 & 314 & 6,506 & 1,092 \\
\hline 163 & 0.86 & 7,630 & 0 & 33,177 & 3,120 & 0 & 750 & 1,176 & 93 & 358 & 6,114 & 1,026 \\
\hline
\end{tabular}




\section{Tab. A2: Actual energy consumption and optimal energy requirements $\mathrm{MJ} / \mathrm{ha}^{-1}$ - Part 2}

\begin{tabular}{|c|c|c|c|c|c|c|c|c|c|c|c|}
\hline \multicolumn{11}{|c|}{ Optimal energy requirements $\left(\mathrm{MJ} / \mathrm{ha}^{-1}\right)$} & \multirow[t]{2}{*}{ ESTR $\%$} \\
\hline IRI & FYM & $\mathrm{N}$ & $\mathrm{Ph}$ & Po & PES & WED & $\mathrm{S}$ & $\mathrm{HL}$ & D & MACH & \\
\hline 5,647 & 0 & 28,515 & 1,613 & 0 & 461 & 963 & 81 & 278 & 4,771 & 922 & 35.71 \\
\hline 6,460 & 252 & 36,227 & 1,166 & 0 & 362 & 347 & 44 & 290 & 5,101 & 989 & 26.89 \\
\hline 6,953 & 0 & 42,221 & 905 & 0 & 470 & 517 & 64 & 289 & 5,234 & 1,034 & 23.28 \\
\hline 6,160 & 32 & 30,412 & 1,805 & 0 & 533 & 539 & 84 & 275 & 5,120 & 988 & 14.17 \\
\hline 6,970 & 315 & 42,155 & 837 & 1,205 & 395 & 527 & 83 & 320 & 5,523 & 1,082 & 20.13 \\
\hline 7,035 & 181 & 38,490 & 1,466 & 472 & 594 & 545 & 72 & 308 & 5,385 & 1,055 & 14.01 \\
\hline 6,385 & 0 & 33,014 & 1,542 & 641 & 437 & 372 & 57 & 292 & 4,952 & 977 & 20.91 \\
\hline 6,157 & 239 & 34,363 & 1,271 & 0 & 383 & 391 & 55 & 284 & 4,885 & 956 & 29.59 \\
\hline 5,479 & 0 & 25,819 & 1,584 & 0 & 439 & 708 & 78 & 278 & 4,616 & 893 & 33.27 \\
\hline 5,971 & 0 & 26,113 & 1,264 & 0 & 441 & 519 & 78 & 286 & 4,714 & 922 & 40.65 \\
\hline 6,858 & 394 & 35,372 & 2,141 & 618 & 660 & 528 & 76 & 315 & 5,356 & 1,021 & 27.77 \\
\hline 5,593 & 0 & 28,209 & 1,609 & 0 & 300 & 1,059 & 83 & 276 & 4,849 & 913 & 30.30 \\
\hline 6,880 & 0 & 37,052 & 829 & 0 & 367 & 332 & 55 & 291 & 5,152 & 1,001 & 26.52 \\
\hline 5,689 & 0 & 22,959 & 1,690 & 0 & 538 & 544 & 77 & 281 & 4,637 & 899 & 12.67 \\
\hline 5,879 & 0 & 27,464 & 1,580 & 0 & 437 & 693 & 70 & 274 & 5,030 & 954 & 31.17 \\
\hline 5,419 & 0 & 25,006 & 1,575 & 0 & 500 & 588 & 77 & 277 & 4,508 & 883 & 26.74 \\
\hline 6,408 & 0 & 30,490 & 1,247 & 0 & 459 & 491 & 43 & 295 & 5,238 & 993 & 23.92 \\
\hline 5,476 & 0 & 26,505 & 1,584 & 0 & 500 & 588 & 74 & 279 & 4,619 & 899 & 32.78 \\
\hline 6,603 & 0 & 34,698 & 1,582 & 0 & 418 & 983 & 77 & 288 & 5,281 & 1,009 & 22.11 \\
\hline 6,118 & 0 & 26,162 & 1,174 & 0 & 428 & 503 & 79 & 289 & 4,757 & 931 & 41.31 \\
\hline 5,593 & 0 & 28,209 & 1,609 & 0 & 541 & 869 & 83 & 276 & 4,629 & 913 & 39.38 \\
\hline 6,046 & 0 & 32,828 & 1,439 & 0 & 524 & 949 & 81 & 279 & 4,854 & 957 & 21.86 \\
\hline 6,431 & 25 & 33,779 & 1,497 & 605 & 426 & 364 & 56 & 292 & 4,978 & 981 & 28.79 \\
\hline 6,146 & 0 & 28,781 & 1,332 & 0 & 461 & 495 & 49 & 293 & 5,047 & 963 & 27.03 \\
\hline 6,530 & 0 & 35,336 & 1,694 & 0 & 388 & 1,086 & 81 & 288 & 5,227 & 1,004 & 27.49 \\
\hline 6,617 & 0 & 29,397 & 2,375 & 141 & 369 & 897 & 57 & 301 & 5,254 & 1,005 & 33.20 \\
\hline 5,527 & 0 & 24,050 & 1,576 & 0 & 464 & 588 & 72 & 280 & 4,606 & 893 & 46.00 \\
\hline 5,647 & 0 & 28,515 & 1,613 & 0 & 311 & 1,081 & 81 & 278 & 4,908 & 922 & 35.70 \\
\hline 6,437 & 350 & 35,288 & 1,671 & 0 & 445 & 524 & 44 & 290 & 5,246 & 988 & 26.48 \\
\hline 6,728 & 3 & 38,665 & 1,108 & 0 & 86 & 1,157 & 71 & 286 & 5,512 & 1,014 & 28.14 \\
\hline 6,083 & 0 & 25,331 & 1,918 & 0 & 456 & 602 & 69 & 287 & 4,780 & 940 & 26.09 \\
\hline 6,397 & 0 & 33,072 & 1,534 & 636 & 437 & 371 & 57 & 292 & 4,962 & 978 & 20.55 \\
\hline 5,479 & 19 & 25,766 & 1,551 & 0 & 491 & 572 & 75 & 277 & 4,539 & 889 & 35.82 \\
\hline 6,234 & 235 & 35,651 & 1,946 & 281 & 671 & 1,052 & 83 & 293 & 5,017 & 980 & 28.53 \\
\hline 5,600 & 0 & 25,476 & 1,778 & 183 & 456 & 536 & 79 & 280 & 4,740 & 918 & 25.52 \\
\hline 6,472 & 202 & 35,702 & 1,417 & 0 & 494 & 625 & 54 & 281 & 5,076 & 978 & 26.57 \\
\hline 5,519 & 0 & 25,526 & 1,542 & 0 & 495 & 575 & 73 & 279 & 4,583 & 894 & 35.06 \\
\hline 5,721 & 0 & 27,949 & 1,592 & 0 & 420 & 925 & 74 & 277 & 4,880 & 920 & 38.29 \\
\hline 6,858 & 394 & 35,372 & 2,141 & 618 & 660 & 528 & 76 & 315 & 5,356 & 1,021 & 26.74 \\
\hline 6,620 & 86 & 36,741 & 1,342 & 617 & 244 & 963 & 93 & 301 & 5,415 & 1,040 & 27.27 \\
\hline 5,779 & 0 & 30,122 & 1,661 & 180 & 680 & 1,066 & 90 & 278 & 4,697 & 947 & 16.30 \\
\hline 5,616 & 0 & 27,998 & 1,631 & 0 & 602 & 799 & 83 & 277 & 4,588 & 914 & 30.15 \\
\hline 6,880 & 0 & 37,052 & 829 & 0 & 367 & 332 & 55 & 291 & 5,152 & 1,001 & 27.01 \\
\hline 5,755 & 0 & 23,225 & 1,674 & 0 & 468 & 550 & 68 & 286 & 4,757 & 914 & 11.63 \\
\hline 5,849 & 0 & 26,971 & 1,572 & 0 & 511 & 615 & 70 & 273 & 4,899 & 949 & 32.86 \\
\hline 5,419 & 0 & 25,006 & 1,575 & 0 & 500 & 588 & 77 & 277 & 4,508 & 883 & 27.34 \\
\hline
\end{tabular}

